\title{
Obese and Diabetes: Two Mutant Genes Causing Diabetes-Obesity Syndromes in Mice*
}

\author{
D. L. Coleman \\ The Jackson Laboratory, Bar Harbor, Maine, USA
}

\begin{abstract}
Summary. The diabetes syndromes produced by the two single gene mutations, obese (ob), and diabetes $(d b)$ are identical when both genes are expressed on the same inbred background, whereas on different backgrounds the syndrome changes from a severeobesity, moderate-diabetes to a severe life-shortening diabetes. The same initial sequence of events occurs in both conditions. Increased secretion of insulin and hyperphagia is followed by moderate hyperglycaemia with a further compensatory increase in insulin secretion followed by an expansion of the beta-cell mass. On the BL/ 6 inbred background, hypertrophy and hyperplasia of the beta cells continues until hyperglycaemia is controlled, whereas on the BL/Ks background, beta cell expansion fails and islet atrophy occurs causing insulinopenia, marked hyperglycaemia, and severe diabetes. The data presented here suggest that hyperphagia, hyperinsulinaemia, or both, early in development trigger the abnormal sequence of metabolic events leading to the obesity-diabetes state. These primary events interact with unknown genetic modifiers to produce either a juvenile or maturity-onset type of diabetes. An understanding of the mode of action of these background modifiers influencing the severity of diabetes in mice should lead to a better understanding of the ways in which unknown genetic and environmental factors contribute to human diabetes.
\end{abstract}

Key words: Diabetes, obesity, hyperphagia, hyperinsulinaemia, mice, genetics.

\footnotetext{
* Based on the Claude Bernard Lecture delivered to the European Association for the Study of Diabetes in Geneva on September 30, 1977
}

Diabetes mellitus in man has been defined as a disorder associated with a degree of hyperglycaemia inappropriate to the metabolic situation at the time of analysis. Diabetes is of two types: juvenile, occurring early in life characterized by insulinopaenia, marked hyperglycaemia, glycosuria and metabolic defects in all pathways modulated by insulin; and maturityonset diabetes occurring later in life in association with obesity and characterized by many of the same metabolic defects as juvenile diabetes. However, insulinopaenia is not characteristic of the early development of maturity-onset diabetes, instead moderate hyperinsulinaemia and insulin resistance contribute to the development of obesity.

The animal models available for diabetes research (Table 1) are most often more like maturityonset diabetes in man. Obesity is a consistent factor and insulinopaenia is rare. However, the time of gene

Table 1. Diabetes-obesity syndromes in rodents

\begin{tabular}{|c|c|c|}
\hline \multicolumn{3}{|l|}{ Single gene mutations } \\
\hline Mice: Gene Name & Inheritance & Chromosome \\
\hline Yellow $\left(A^{y}, A^{v y}, A^{i y}\right)$ & $\begin{array}{l}\text { Autosomal } \\
\text { dominant }\end{array}$ & 2 \\
\hline Obese $(o b)$ & $\begin{array}{l}\text { Autosomal } \\
\text { recessive }\end{array}$ & 6 \\
\hline Diabetes $\left(d b, d b^{2 J}, d b^{3 J}, d b^{a d}\right)$ & $\begin{array}{l}\text { Autosomal } \\
\text { recessive }\end{array}$ & 4 \\
\hline Fat (fat) & $\begin{array}{l}\text { Autosomal } \\
\text { recessive }\end{array}$ & $?$ \\
\hline \multicolumn{3}{|l|}{ Rats: } \\
\hline Fatty $(f a)$ & $\begin{array}{l}\text { Autosomal } \\
\text { recessive }\end{array}$ & $?$ \\
\hline \multicolumn{3}{|l|}{ Inbred strains } \\
\hline $\begin{array}{c}\text { Mice: } \\
\text { NZO } \\
\text { KK }\end{array}$ & $\begin{array}{l}\text { Polygenic } \\
\text { Polygenic }\end{array}$ & $\begin{array}{l}? \\
?\end{array}$ \\
\hline
\end{tabular}


expression at about two weeks of age is within the time period of juvenile expression. The severity and clinical course of the diabetes produced depends on the interaction of the mutant gene with the inbred background rather than the action of the gene itself. Thus on one inbred background a well-compensated, maturity onset type diabetes, compatible with near normal life is observed whereas on another inbred background the syndrome presents as a juvenile-type diabetes with insulinopaenia, islet cell degeneration, marked hyperglycaemia, some ketosis and a much shortened lifespan. Unfortunately, vascular, retinal and the other complications of diabetes are not seen consistently in these rodent syndromes. It seems that the severely diabetic animal either does not live long enough to develop these complications or that rodents are particularly resistant to those complications that commonly afflict human diabetics. Several comprehensive bibliographies and excellent reviews of the various studies carried out with each of these syndromes in animals have been published $[2,3,19$, $30,31,32]$.

This presentation will be restricted primarily to the research undertaken by my colleagues and myself with the two mouse mutations; diabetes $(d b)$, and obese $(o b)$. Both mutations have been extensively studied by numerous investigators in attempts to define the primary lesion causing the syndrome. As yet, the primary defect remains illusive, although several possibilities are becoming increasingly plausible in the light of current research. Although the metabolic abnormalities associated with both obese and diabetes have many similarities with regard to the overall progression of the obesity-diabetes state, the documentation of two single genes on separate chromosomes makes it unlikely that the two syndromes are caused by the same primary lesion. However, the marked similarity between the two mutants when maintained on the same genetic background implies that the defects may occur in the same metabolic pathway.

Both syndromes vary in degree, rather than the developmental profile of the disease. Signs include hyperphagia, some degree of hyperinsulinaemia, hyperglycaemia (either transient or sustained) and marked obesity. Thermoregulatory defects, hypogonadism, and functional sterility are typical features. The activities of many enzymes in many pathways (lipogenesis, gluconeogenesis, glycolysis) have been studied and any abnormalities observed usually reflect the degree of hyperinsulinaemia. The most notable exceptions occur with those enzymes involved in gluconeogenesis that remain elevated in spite of high plasma insulin concentration [7, 20,33]. Hyperplasia and hypertrophy of the islets of Langer- hans are associated with both syndromes. Insulin resistance associated with a loss of receptor sites causes excessive insulin demand. Whether the increase in number and size of the islets can keep up with the abnormal metabolic demand for insulin to control the diabetes depends in both instances on the inbred background on which either mutation is maintained $[9,21]$.

The Obese (ob) Mouse (Chromosome 6). The obese mutation occurred in a noninbred stock [23] but was established later, and has been maintained, in the C57BL/6J (BL/6) strain. BL/6 obese mice are characterized by marked obesity, hyperphagia, transient hyperglycaemia and markedly elevated plasma insulin concentrations associated with an increase in number and size of the beta cells of the islets of Langerhans $[9,17]$. The mutation is autosomal recessive and homozygous mutants of both sexes are infertile. Obese mutants are obtained by mating known heterozygotes. The rate of liver and adipose tissue lipogenesis is more than doubled [29], although this increase is not strictly proportional to the circulating insulin concentration ( 10 to 20 times normal). Marked insulin resistance is associated with a loss in insulin receptors in several tissues $[26,27]$. This loss of receptor sites with obesity seems general in all obesity mutants studied and may be an attempt by the animal to protect itself against the hypoglycaemic effect of massive levels of circulating insulin [2]. Those enzymes involved in gluconeogenesis which normally are decreased in the hyperinsulinaemic state remain elevated in obese mice $[20,33]$. This abnormality occurs early in development and may precede the loss of insulin receptor sites in target cells, and could represent a primary defect contributing to the hyperglycaemia. A primary metabolic disturbance in the adipocyte has been postulated in obese mice since increased adipocyte size has been observed as early as 14 days of age well before any obesity or hyperinsulinaemia are observed [25].

The Diabetes (db) Mouse (Chromosome 4). Diabetes $(\mathrm{db})$, an autosomal recessive mutation, occurred in the $\mathrm{C} 57 \mathrm{BL} / \mathrm{KsJ}$ (BL/Ks) inbred strain and on this background is characterized by obesity, hyperphagia, and a severe diabetes with marked hyperglycaemia $[7,22]$. Increased plasma insulin concentration is observed as early as 10 days of age [10]. The concentration of insulin peaks at 6 to 10 times normal by 2 to 3 months of age then drops precipitously to near normal levels. Prior to the fall in plasma insulin concentration, the most consistent morphological feature of the islets of Langerhans appears to be hyperplasia and hypertrophy of the beta cells in an attempt to 
produce sufficient insulin to control blood glucose concentration at physiological levels. The drop in plasma insulin concentration is concomitant with islet atrophy and rapidly rising blood glucose concentrations that remain over $400 \mathrm{mg}$ per $100 \mathrm{ml}$ until death at 5 to 8 months [7]. Compared with other obesity mutants the diabetic condition is more severe and the lifespan is markedly decreased.

The activities of several key gluconeogenic enzymes are increased in both young and adult diabetes mice as compared with controls $[4,7]$ in spite of the higher than normal circulating levels of plasma insulin. In contrast the activities of the insulin dependent enzymes such as glucokinase, glucose 6-phosphate dehydrogenase, citrate lyase, malic enzyme and acetyl-CoA synthetase are increased indicating a normal response to elevated concentrations of plasma insulin [7]. As in the obese mouse, insulin resistance coupled with a disappearance of receptor sites has been a consistent finding in most tissues studied [26].

A second allele $\left(\mathrm{d} b^{2 J}\right)$ arose shortly after the original mutation was discovered at the Jackson Laboratory. This mutation in the strain of origin exhibited mild diabetes with markedly elevated plasma insulin concentrations sustained throughout a nearly normal lifespan. The phenotypic expression was identical to that observed with the BL/ 6 obese $(o b)$ mutant and was distinctly unlike the original diabetes $(d b)$ mutation on the $\mathrm{BL} / \mathrm{Ks}$ background [21]. When the $d b^{2 I}$ allele was introduced to the $\mathrm{BL} / \mathrm{Ks}$ background, no differences in gene expression were observed between it and the original $d b$ mutation suggesting a marked effect of genetic background on the expression of the gene. Another spontaneous mutation $\left(d b^{33}\right)$ occurred in the $129 / \mathrm{J}$ strain at the Jackson Laboratory and presented as a severe obesity with hypoglycaemia rather than hyperglycaemia, coupled with marked hyperinsulinaemia and massively enlarged islets of Langerhans (Leiter and Coleman, unpublished). This allele has not been placed on the $\mathrm{BL} / \mathrm{Ks}$ background and the unusual clinical manifestations may be due to the allele itself or the background on which it is maintained. Falconer and Isaacson [14] described a mutant in a heterogenous stock that was named adipose ( $a d)$. This was subsequently found to be an allele of diabetes and the gene symbol was changed from $a d$ to $d b^{a d}$. No differences have been observed between $d b$ and $d b^{a d}$ when the alleles are maintained in the same inbred background [28].

Homozygous diabetes mice are sterile and heterozygous carriers must be used to propagate these mutants. In this regard, use has been made of the close linkage of the coat colour gene, misty $(m)$ to diabetes to develop two new congenic strains, $\mathrm{BL} / 6$ - $m d b$ and $\mathrm{BL} / \mathrm{Ks}-m d b$. The misty gene was transferred from inbred misty stocks by crossing $\mathrm{BL} / 6-\mathrm{m} / \mathrm{m}$ with $\mathrm{BL} / 6-d b /+$ mice and $\mathrm{BL} / \mathrm{Ks}-m / m$ with $\mathrm{BL} / \mathrm{Ks}-$ $d b /+$ mice to produce inbred $\mathrm{BL} / 6$ and $\mathrm{BL} / \mathrm{Ks}$ strains of mutant mice in which the misty gene was maintained in repulsion on the opposite chromosome from the diabetes gene. This procedure facilitates identification of the heterozygotes $(+m / d b+)$ required for breeding, which are thin and black, as opposed to normals $(+m /+m)$, thin and gray, and mutants $(d b+/ d b+)$, fat and black [11]. After several hundred matings of this type a crossover was identified between the diabetes and misty locus providing mice carrying misty and diabetes coupled on the same chromosome. These coupled stocks have been extremely valuable in identifying future diabetes mice $(m d b / m d b)$ by the expression of the misty (gray) coat-color as early as 4 days post partum well before any hyperinsulinaemia, obesity or other clinical symptoms are apparent [10]. It must be emphasized that these new stocks provide us with tools for research that are recognizable by coat color and yet are identical in all respects to the original mutation as expressed on the particular inbred background. These stocks should not be confused with those stocks used by others, "DBM", [5] and, " $d b m$ ", [18] which are not inbred strains and have elements of several inbred strains contaminating the genetic background (see below).

Effects of Inbred Background (Table 2). The syndrome produced in $\mathrm{BL} / \mathrm{Ks}$ diabetes $(d b)$ mice, while similar in early development to that of BL/ 6 obese $(o b)$ mice, has a more severe diabetes-like condition and a less pronounced obesity. However, both mutations when maintained on the same inbred background exhibit identical syndromes from 3 weeks of age on $[9,21]$. Both diabetes and obese mice of the $\mathrm{BL} / \mathrm{Ks}$ strain have the severe diabetes characterized by insulinopaenia and islet atrophy, whereas both mutations maintained on the BL/ 6 strain have mild diabetes characterized by islet hypertrophy and hyperplasia of the beta cells. Islet hypertrophy is either sustained or followed by atrophy depending on modifiers in the genetic background rather than the specific action of the mutant gene. The markedly different obesity-diabetes states exhibited when obese and diabetes mice are on different backgrounds points out the importance of strict genetic control in studies with all types of obese-hyperglycaemic mutants. Genetic studies [11] have shown that the modifiers leading to islet hypertrophy and well-compensated diabetes compatible with a near normal lifespan are dominant to those factors causing severe diabetes. 
Table 2. Effect of genetic background on the diabetic syndromes

\begin{tabular}{|c|c|c|}
\hline \multirow[b]{2}{*}{ Locus } & \multicolumn{2}{|l|}{ Strain } \\
\hline & $\mathrm{C} 57 \mathrm{BL} / 6 \mathrm{~J}$ & C57BL/KsJ \\
\hline Obese $(a b)$ & $\begin{array}{l}\text { Marked obesity, mild diabetes, islet hyperplasia, hyper- } \\
\text { insulinaemia }\end{array}$ & $\begin{array}{l}\text { Obesity, severe diabetes, transient hyperinsulinaemia, } \\
\text { islet atrophy }\end{array}$ \\
\hline $\begin{array}{l}\text { Diabetes } \\
\left(d b, d b^{2 J}, d b^{a d}\right)\end{array}$ & $\begin{array}{l}\text { Marked obesity, mild diabetes, islet hyperplasia, hyper- } \\
\text { insulinaemina }\end{array}$ & $\begin{array}{l}\text { Obesity, severe diabetes, transient hyperinsulinaemia, } \\
\text { islet atrophy }\end{array}$ \\
\hline Agouti $\left(A^{y}, A^{v y}\right)$ & $\begin{array}{l}\text { Moderate obesity, minimal diabetes, some islet hyper- } \\
\text { plasia }\end{array}$ & Same as on BL/ 6 background \\
\hline Fat (fat) & $\begin{array}{l}\text { HRS/J background: obesity, normal or hypoglycaemia, } \\
\text { hyperinsulinaemia, islet hypertrophy and beta cell } \\
\text { degranulation }\end{array}$ & Same as on HRS/J background \\
\hline
\end{tabular}

Two other mutations, yellow and fat, cause similar diabetes-syndromes and yet have identical symptoms on both inbred backgrounds (Table 2). This may suggest that the primary insult caused by these mutations is not as severe as that for obese and diabetes and that this more gradual initiation of obesity permits the host genome to make a response (islet hypertrophy) compatible with life rather than islet atrophy, insulinopaenia, and life-shortening diabetes.

The $\mathrm{BL} / \mathrm{Ks}$ strain is the only strain studied to date that shows nearly a 100 per cent incidence of severe diabetes in conjunction with either the diabetes or obese mutation. Most strains exhibit a milder syndrome with males being most severely afflicted. Studies with cultured postnatal islet cells have revealed increased synthesis and secretion of glucagon as early as 5 days of age in cells isolated from pancreases of $\mathrm{BL} / \mathrm{Ks}$ diabetes mice but not those of $\mathrm{BL} / 6$ diabetes mice (Leiter and Coleman, unpublished). This abnormality, if present in vivo, could cause excess glucagon secretion early in development and predispose the beta cell to degeneration typical of $\mathrm{BL} /$ Ks but not BL/ 6 diabetes mice.

The inbred background may be implicated in the control of the number and size of the fat cells in obesity mutants. The obese $(o b)$ mutation on the $\mathrm{BL} /$ 6 background is one of two rodent models characterized by a hypertrophic-hyperplastic type of obesity with both an enlargement and an increase in number of individual fat cells contributing to the obesity. In contrast the phenotypically similar diabetes (db) mutation, maintained on the BL/Ks background, is characterized by adipocyte hypertrophy only [24]. This difference may be related to the effects of the obese and diabetes genes themselves, or may be related to the different genetic backgrounds used in these studies.
Parabiosis Experiments. Having obese and diabetes on the same histocompatible backgrounds has permitted studies of parabiotic unions of normal with mutant mice and provided some insight into the nature of the primary lesions in these mutants. Unions of diabetes $(d b / d b)$ with normal mice (Figure 1) resulted in the death of the normal mouse, apparently of starvation, within 3 to 4 weeks after surgery [8]. Our interpretation of this finding is that the diabetes partner produces, but does not respond to, a satiety factor that prevents overeating. In parabiosis this factor crosses into the circulation of the normal partner where it acts on the normal partner's satiety centre to inhibit eating, producing subsequent starvation and death. Parabiosis of two diabetes mice is not lethal to either presumably because both have defective satiety centres. When obese $(o b / a b)$ mice were parabiosed with diabetes $(d b / d b)$ mice, the obese partner lost weight and died of starvation, while no abnormal changes were observed in the diabetes partner (6; Figure 1). This suggests that obese mice are like normal mice with normal satiety centres responsive to satiety factor. Both partners survive in unions of obese with normal mice, suggesting that the obese partner, unlike the diabetes mouse, does not produce sufficient satiety factor to turn off the normal partner's eating drive. However, obese mice in such pairs eat less and gain weight less rapidly than obese with obese pairs [6]. This observation suggests that the normal partner provides a humoral (satiety) factor that regulates food consumption and weight gain in the obese partner. These experiments suggest that the obese mouse is unable to produce sufficient satiety factor to regulate its food consumption, whereas the diabetes mouse produces satiety factor, but cannot respond to it because of a defective satiety centre. This would explain the identical obese-hyper- 
Table 3. Body weight and percentage body fat composition in pair-fed mutants and normal mice

\begin{tabular}{|c|c|c|c|c|c|c|c|}
\hline \multirow[b]{2}{*}{ Genotype } & \multirow[b]{2}{*}{ Age } & \multicolumn{3}{|l|}{ Fed ad libitum } & \multicolumn{3}{|l|}{ Pair-fed } \\
\hline & & Body weight $^{\mathrm{a}}$ & $\begin{array}{l}\text { Weight } \\
\text { change }\end{array}$ & Fat & Body weight & $\begin{array}{l}\text { Weight } \\
\text { change }\end{array}$ & Fat \\
\hline & Days & & $\mathrm{g}$ & $\%$ & $\mathrm{~g}$ & $\mathrm{~g}$ & $\%$ \\
\hline$+/ ?$ & $\begin{array}{l}20 \pm 2 \\
48 \pm 2\end{array}$ & $\begin{array}{l}14.6 \pm 0.5^{b} \\
26.1 \pm 0.9\end{array}$ & 11.5 & $\begin{array}{l}9.5 \pm 0.4 \\
9.1 \pm 0.8\end{array}$ & $\begin{array}{l}15.1 \pm 0.6 \\
21.4 \pm 0.8\end{array}$ & $\overline{6.3}$ & $14.9 \pm 0.8$ \\
\hline$o b / o b$ & $\begin{array}{l}20 \pm 2 \\
48 \pm 2\end{array}$ & $\begin{array}{l}17.0 \pm 0.5 \\
38.6 \pm 0.4\end{array}$ & 21.6 & $\begin{array}{l}23.8 \pm 1.1 \\
42.3 \pm 1.4\end{array}$ & $\begin{array}{l}17.1 \pm 0.4 \\
25.6 \pm 1.0\end{array}$ & $\overline{8.5}$ & $43.7 \pm 1.0$ \\
\hline$d b / d b$ & $\begin{array}{l}20 \pm 2 \\
48 \pm 2\end{array}$ & $\begin{array}{l}16.8 \pm 0.4 \\
38.2 \pm 0.5\end{array}$ & 21.4 & $\begin{array}{l}24.3 \pm 0.9 \\
36.8 \pm 0.8\end{array}$ & $\begin{array}{l}16.6 \pm 0.5 \\
24.3 \pm 1.2\end{array}$ & $\overline{7.7}$ & $41.7 \pm 0.7$ \\
\hline
\end{tabular}

${ }^{a}$ Body weights and percentage fat was obtained at 0 time on 4 mice of each genotype of comparable starting weight and after 4 weeks on dietary regimen for experimental mice. Food consumption ranged from 180 to 250 twenty mg Noyes pellets per day during the 4 week test period

${ }^{b}$ Figures represent average value \pm SEM of 4 mice in each group
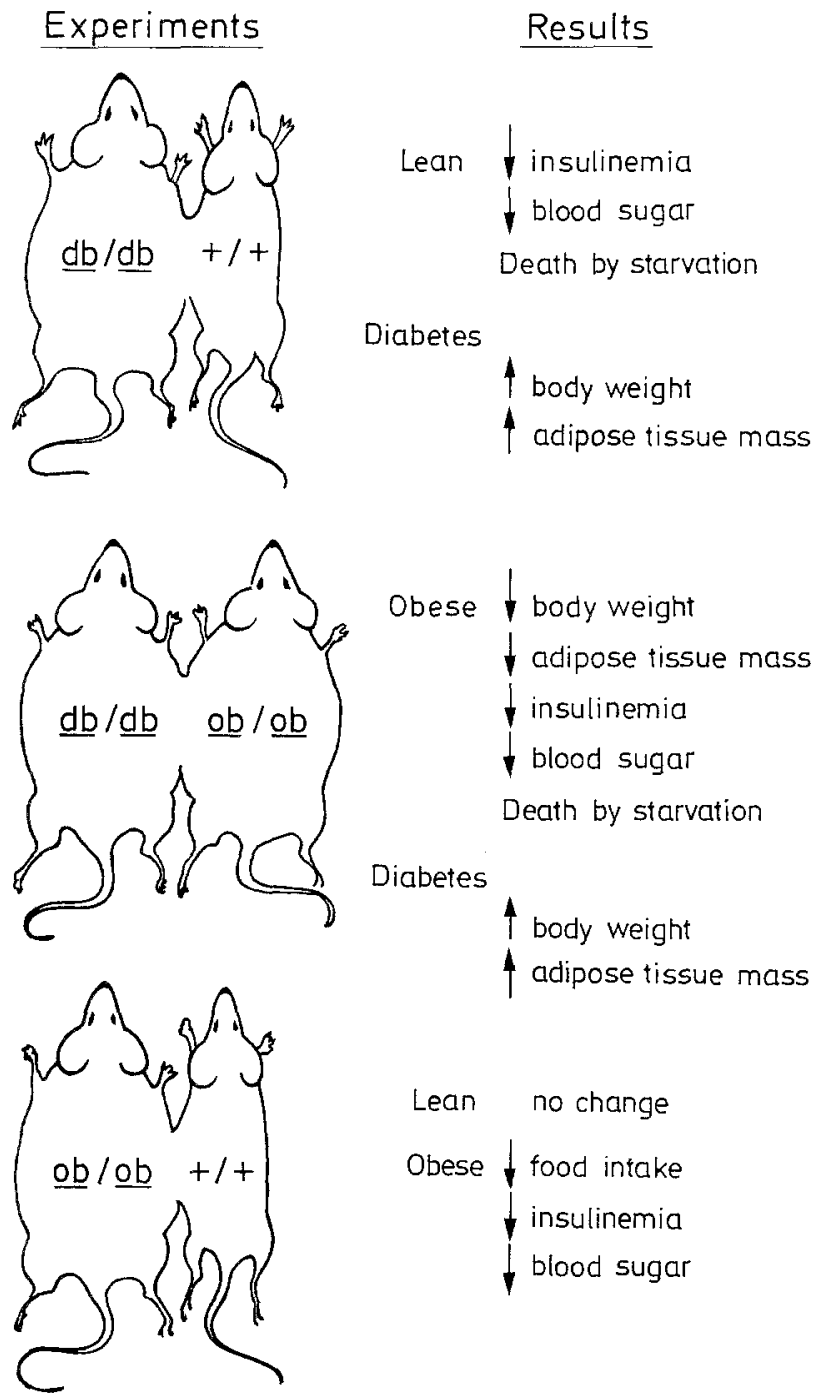

Diabetes
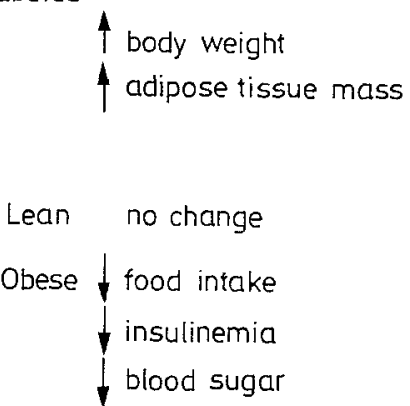

Fig. 1. Schematic representation of experimental results obtained between all combinations of normal, obese, and diabetes mice. Parabiotic pairs of like genotypes all survive and maintain their typical metabolic features glycaemic syndromes produced by these two unrelated genes when they are acting in identical genetic backgrounds.

Feed Efficiency Studies. Both the diabetes and obese mutants on either inbred background are characterized by hyperphagia and obesity. Our studies with obese and diabetes mice pair-fed normal amounts of food on a normal feeding schedule indicate that, even when food intake is normal, conversion of foodstuffs to fat is favoured and the rate of weight gain per gram of food consumed is increased over that seen in sibling controls (Table 3 ). In these experiments normal mice were trained to press a bar to obtain food. The obese and diabetes mice in separate cages received their food only when the normal mouse pressed the bar. Thus all subjects (mutant and normal) received the same amount of food on the same time schedule. Table 3 shows that both mutants gained more weight on the same amount of food in the 28 day period of the experiment. Further, the percentage of body fat accumulated in both obese mutants was increased to values similar to mutants fed ad libitum (around $40 \%$ ) even under these conditions of relative food deprivation. The weight gain for the normal mouse was somewhat less than mice fed ad libitum and there was a tendency to store more food as fat $(14.9 \%$ vs $9.5 \%$ ad libitum) suggesting that under these conditions a slightly increased feed efficiency occurs. Cox and Powley [12] demonstrated similar increased feed efficiencies in $\mathrm{BL} / 6 d b / d b$ mice derived from our colony. Studies with the obese mouse [16] and the fatty rat [35] indicate that increased feed efficiency and accumulation of excess fat in spite of normal food intake may be a consistent feature of all obesity mutants. Decreased energy expenditure of all these mutants, although undoubtedly a factor, cannot 
totally account for this increased food efficiency and it must be concluded that although hyperphagia is always present under food ad libitum conditions, it is not a necessary prerequisite for the development of obesity.

\section{Discussion}

A primary hypothalamic defect could be involved in both mutants. Both are infertile, have defects in thermoregulation, and are hyperphagic, all evidence which supports a hypothalamic defect. The best documentation for such a defect is found in the diabetes $(d b)$ mouse which may have a defective satiety centre preventing it from responding to satiety factor [8]. Although these studies appear very clear-cut, they must be interpreted with caution since the syndrome in the diabetes mouse differs in many respects from the classical syndrome in which the ventromedial nucleus (VMH) is destroyed by electrolytic lesioning. The genetic lesion probably involves a defect in a much more discrete area of the hypothalamus than is destroyed by chemical or electrolytic lesions and many of the normal functions of the region other than satiety may be preserved.

The obese $(o b)$ mouse is phenotypically identical to the diabetes mouse when maintained on the same genetic background suggesting that this syndrome might also be caused by a defective hypothalamus. However, our results with obese mice in parabiosis with diabetes mice suggest that obese mice can respond to satiety factor and that at least that part of the hypothalamus involving satiety is normal [6]. Studies with obese and normal mice in parabiosis have established that food consumption and rate of weight gain was regulated in the obese partner by something coming from the normal partner. This suggested that the obese mouse cannot produce satiety factor in sufficient amounts to control its appetite. Strautz [34] has shown that transplantation of normal islets to obese mice stablized rate of weight gain and reduced both hyperglycaemia and hyperinsulinaemia. These studies imply that the missing satiety factor may be pancreatic in origin. Similar islet transplant studies undertaken by others with obese mice have not been able to repeat these results and this hypothesis, until confirmed, must be considered with caution. Studies by Gates et al. [15] using the genetically dissimilar NZO obesity model have established the existence of a pancreatic, but non-beta cell factor, that will cure NZO mice. It is hard to see how a single factor missing from NZO mice could alleviate the syndrome entirely since the condition is caused by the interaction of several genes and must represent more than one primary defect. Still to be evaluated as potential curative factors are somatostatin, pancreatic polypeptide, and serotonin, all compounds contained in various cells of the pancreas.

The hypothalamus regulates food consumption via two mechanisms. The ventromedial region (satiety centre) exerts an inhibitory influence on the lateral hypothalamus (feeding centre) thereby regulating food intake. The lateral hypothalamus $(\mathrm{LH})$ stimulates insulin secretion by the pancreas via impulses through the vagus nerve. A defective satiety centre, as postulated in the diabetes mouse, would cause the LH to fire continuously causing excess insulin secretion very early in development prior to any hyperphagia or signs of obesity. Our studies [10] with preclinical diabetes $(d b)$ mice showed this to be the case and support the defective satiety centre hypothesis.

Another attractive hypothesis regarding the primary defect in the obese mouse is a defect intrinsic to the adipocyte itself. Joosten and van der Kroon [25] showed that increases in the size of the individual fat cells in obese mice could be observed as early as 14 days, prior to any evidence of either obesity or hyperglycaemia (24-30 days). These data suggested that the primary defect may be in the metabolism of the individual fat cell. Recent studies [1] using fat pads from obese or normal mice transplanted to the kidney capsule of obese or normal mice showed that the transplanted fat pad took on the morphological characteristics of the host, i. e. normal fat to an obese host caused marked enlargement of the fat cells whereas obese fat to normal host caused normalization of fat tissue. The same results were obtained with fat pads from diabetes and yellow mice and as well as those made obese with the gold thioglucose (GTG) (Ashwell, personal communication). These authors conclude that none of the obesities ( $o b, d b, A^{y}$, or GTG) are caused by defects in the fat pad itself but rather the morphology and development of the fat cell depends on the environment in which it is located. The availability of the congenetically athymic nude mouse which does not reject either allografts or xenografts and will accept tissue grafts from unrelated strains and even other species should make this technique applicable to all obesity models as well as human beings.

Both of these syndromes are characterized in the earliest stages by varying degrees of hyperphagia and hyperinsulinaemia. Hyperphagia could initiate changes in the beta cells causing hyperinsulinaemia or, alternatively, a primary defect in the beta cell could cause excessive insulin secretion thereby causing the hyperphagia. Either mechanism sets up a cycle of overeating, increased plasma insulin and 
further overeating. The question of which comes first is probably academic since neonatal rodents are hyperphagic from birth until weaning. The only satiety signal that is recognizable by the neonate is fullness of gut [13]. Growth rate and fat deposition of the pup is regulated solely by competition for milk among siblings and varies greatly with the size of the litter. Satiety mechanisms develop in a systematic fashion around the time of weaning and thereafter. In the case of the diabetic mouse, hyperphagia persists because it cannot recognize satiety factor whereas in the obese mouse hyperphagia persists because satiety factor is never produced. Accordingly, the hyperinsulinaemia detectable by 12 days in diabetes mice would be a result of an unregulated lateral hypothalamus providing overstimulation to the pancreas rather than resulting from hyperphagia. Even though continuing hyperphagia throughout life contributes to the development of the massive obesity in these mutants, hyperphagia is not a necessary prerequisite to obesity, and if prevented, the mutants still gain some excess weight and accumulate lipid in the same proportion as that seen in mutants fed ad libitum.

Hyperphagia or hyperinsulinaemia would lead to obesity and beta cell hyperactivity causing either compensatory hypertrophy and hyperplasia of the beta cells or beta cell exhaustion and atrophy. In early development, continued hyperphagia causes increased insulin secretion followed by increased hyperphagia which in turn causes further secretion of insulin. Hyperinsulinaemia, as a primary defect would have the same consequences, sustaining and constributing to hyperphagia, to more insulin secretion, and to other metabolic changes characteristic of both mutants. The target organs for insulin become maximally stimulated. Insulin resistance intervenes, probably to protect the animal against what should be the hypoglycaemic effect of the excess insulin. The pancreatic output of insulin is either sustained, thus maintaining grossly elevated concentration of insulin and producing a massive obesity, or islet atrophy occurs causing insulinopaenia, severe diabetes and premature death.

These diabetes models have some aspects of both maturity-onset and juvenile diabetes and each has some application to studies of both. Varying the background on which the mutation is maintained has profound effects on the type of diabetes produced. Investigators wishing to study a model of juvenile type of diabetes could choose either the diabetes or obese mutations on the BL/Ks background whereas those more interested in obesity and a maturity-onset diabetes could choose these same mutants on the BL/ 6 background. An understanding of the mode of action of these modifying genes that change the course of the disease from a severe juvenile type to a more benign obesity or maturity-onset type of diabetes would be an important contribution to the understanding of human diabetes variants.

Dedication and Acknowledgements. This paper is dedicated to Dr. Katharine P. Hummel, an anatomist, and to the late Dr. Margaret M. Dickie, a geneticist, who both did their best to teach me, a biochemist, the fundamentals of their fields of interest. For their attempts to broaden my scope, I am truly grateful.

I would like to acknowledge many years of dedicated effort by two research assistants, Mrs. Dorothy B. Chapman and Mr. Richard H. Copp, without whose help the genetic stocks would not have been developed and maintained nor many of the metabolic investigations undertaken.

Lastly, I should like to acknowledge the active collaboration and encouragement from my colleagues in laboratories throughout the world, especially Dr. Albert E. Renold of the University of Geneva. Without their sustained interest, suggestions, and encouragement, many of these studies would have remained incomplete.

The Claude Bernard Lecture is sponsored by the Paul Neumann Foundation, Paris. This research was supported in part by Research Grants AM 14461 and AM 20725 from the National Institute of Arthritis, Metabolism, and Digestive Diseases; by Research Grant CA 05873 from the National Cancer Institute; and by a grant from the Juvenile Diabetes Foundation. The Jackson Laboratory is fully accredited by the American Association for the accreditation of Laboratory Animal Care.

\section{References}

1. Ashwell, M., Meade, C. J., Medawar, Sir P., Sowter, C.: Adipose tissue: contributions of nature and nurture to the obesity of an obese mutant mouse $(a b / a b)$. Proc. R. Soc. Lond. [Biol.] 195, 343-353 (1977)

2. Assimacopoulos-Jeannet, F., Jeanrenaud, B.: The hormonal and metabolic basis of experimental obesity. Clin. Endocrinol. Metabol. 5, 337-365 (1976)

3. Bray, G.A., York, D.A.: Genetically transmitted obesity in rodents. Physiol. Rev. 51, 598-646 (1971)

4. Chang, A.Y., Schneider, D. I.: Abnormalities in hepatic enzyme activites during development of diabetes in $a b$ mice. Diabetologia 6, 274-278 (1970)

5. Chick, W.L., Like, A.A.: Studies in the diabetic mutant mouse: IV. DBM, a modified diabetic mutant produced by outcrossing the original strain. Diabetologia 6, 252-256 (1970)

6. Coleman, D. L.: Effects of parabiosis of obese with diabetes and normal mice. Diabetologia 9, 294-298 (1973)

7. Coleman, D. L., Hummel, K.P.: Studies with the mutation, diabetes, in the mouse. Diabetologia 3, 238-248 (1967)

8. Coleman, D. L., Hummel, K.P.: Effects of parabiosis of normal with genetically diabetic mice. Am. J. Physiol. 217, 1298-1304 (1969)

9. Coleman, D.L., Hummel, K.P.: The influence of genetic background on the expression of the obese $(o b)$ gene in the mouse. Diabetologia 9, 287-293 (1973)

10. Coleman, D.L., Hummel, K.P.: Hyperinsulinemia in preweaning diabetes $(d b)$ mice. Diabetologia 10, 607--610 (1974)

11. Coleman, D.L., Hummel, K.P.: Influence of genetic background on the expression of mutations at the diabetes locus in the mouse. II. Studies on background modifiers. Isr. J. Med. 11, 708-713 (1975) 
12. Cox, J.E., Powley, T.L.: Development of obesity in diabetic mice pair-fed with lean siblings. J. Comp. Physiol. Psychol. 91, 347-358 (1977)

13. Epstein, A. N.: Feeding and drinking in suckling rats. In: D. Novin, W. Wyrwicka, and G. Bray (Eds.): Hunger, Basic Mechanisms and Clinical Implications, p. 193-202. New York: Raven Press (1976)

14. Falconer, D. S., Isaacson, J. H.: Adipose, a new inherited obesity of the mouse. J. Hered. 50, 290-292 (1959)

15. Gates, R. J., Hunt, M. I., Lazarus, N. R.: Further studies on the amelioration of the characteristics of New Zealand obese (NZO) mice following transplantation of islets of Langerhans. Diabetologia 10, 401-406 (1974)

16. Goldman, J. K., Bernardis, L. L., Frohman, L. A. Food intake in hypothalamic obesity. Am. J. Physiol. 227, 88-91 (1974)

17. Genuth, S.M., Przybylski, R.S., Rosenberg, D. M.: Insulin resistance in genetically obese hyperglycemic mice. Endocrinology 88, 1230-1238 (1971)

18. Gunnarsson, R.: Function of the pancreatic $\beta$-cell during the development of hyperglycemia in mice homozygous for the mutations diabetes $(d b)$ and misty $(m)$. Diabetologia 11, 431-438 (1975)

19. Herberg, L., Coleman, D.L.: Laboratory animals exhibiting obesity and diabetes syndromes. Metabolism 26, 59-98 (1977)

20. Herberg, L., Major, E., Hennings, U., Gruneklee, D., Freytag, G., Gries, F. A.: Differences in the development of the obese hyperglycemic syndrome in $o b / o b$ and NZO mice. Diabetologia 6, 292-299 (1970)

21. Hummel, K.P., Coleman, D. L., Lane, P. W.: The influence of genetic background on expression of mutations at the diabetes locus in the mouse. I. C57BL/KsJ and C57BL/6J strains. Biochem. Genet. 7, 1-13 (1972)

22. Hummel, K.P., Dickie, M.M., Coleman, D.L.: Diabetes, a new mutation in the mouse. Science 153, 1127-1128 (1966)

23. Ingalls, A.M., Dickie, M.M., Snell, G. D.: Obese, a new mutation in the mouse. J. Hered. 41, 317-318 (1950)

24. Johnson, P. R., Hirsch, J.: Cellularity of adipose depots in six strains of genetically obese mice. J. Lipid Res. 13, 2-11 (1972)
25. Joosten, H.F.P., van der Kroon, P.H.W.: Enlargement of epididymal adipocytes in relation to hyperinsulinemia in obese mice $(o b / o b)$. Metabolism 23, 59-66 (1974)

26. Kahn, C. R., Neville, D.M. Jr., Roth, J.: Insulin receptor interaction in the obese-hyperglycemic mouse. A model of insulin resistance. J. Biol. Chem. 248, 244-250 (1973)

27. Kahn, C. R., Neville, D. M. Jr., Gorden, P., Freychet, P., Roth, $\mathrm{J}$.: Insulin receptor defect in insulin resistance. Studies in the obese-hyperglycemic mouse. Biochem. Biophys. Res. Commun. 48, 135-142 (1972)

28. Lane, P. W.: Mouse News Letter 48, 34 (1973)

29. Loten, E. G., Rabinovitch, A., Jeanrenaud, B.: In vivo studies on lipogenesis in obese hyperglycemic $(o b / o b)$ mice: possible role of hyperinsulinemia. Diabetologia 10, 45-52 (1974)

30. Renold, A.E., Dulin, W. E. (eds.): First Brook Lodge Workshop on Spontaneous Diabetes in Laboratory Animals. Diabetologia 3, 63-286 (1967)

31. Renold, A.E., Cahill, G. F. Jr., Gerritsen, G. C. (eds.): Second Brook Lodge Workshop on Spontaneous Diabetes in Laboratory Animals. Diabetologia 6, 153-370 (1970)

32. Renold, A.E., Chang, A.Y., Muller, W.A. (eds.): Third Brook Lodge Workshop on Spontaneous Diabetes in Laboratory Animals. Diabetologia 10, 491-702 (1974)

33. Seidman, I., Horland, A. A., Teebor, G. W.: Hepatic glycolytic and gluconeogenic enzymes of the obese hyperglycemic mouse. Biochim. Biophys. Acta 146, 600-603 (1967)

34. Strautz, R. L.: Studies of hereditary obese mice $(o b / o b)$ after implantation of pancreatic islets in millipore filter capsules. Diabetologia 6, 306-312 (1970)

35. Zucker, L.M.: Efficiency of energy utilization by the Zucker hereditary obese rat "fatty". Proc. Soc. Exp. Biol. Med. 148, 498-500 (1975)

Received: October 26, 1977

Dr. D. L. Coleman

The Jackson Laboratory

Bar Harbor, ME 04609

USA 